\title{
Enfermeiras*, processo de trabalho, pandemia: onde os caminhos se cruzam
}

\author{
Nurses, work process, pandemic: \\ where paths cross
}

Tatiane Araújo dos Santos

Universidade Federal da Bahia (Salvador). Bahia, Brasil. tadsantos@ufba.br

Deste o surgimento da pandemia do novo Coronavírus, que chega aqui no Brasil por volta do início de 2019, que o trabalho da enfermeira é pauta do dia em declarações de autoridades e na mídia. Um trabalho que sempre foi (e continua, mesmo na pandemia) inviabilizado, recebe agora alguns holofotes. Contudo, os holofotes miram apenas em uma parte deste trabalho: o assistencial.

O processo de trabalho da enfermeira é, na verdade, dual: assistencial-gerencial. Sim, temos dupla atuação. E esse processo de trabalho dual não se separa. Nunca. O que pode ocorrer é que por um determinado período de tempo a enfermeira execute mais o trabalho assistencial ou o gerencial, a depender das demandas da organização e das necessidades dos usuários e da equipe de saúde. A exceção a isto ocorre quando as enfermeiras ocupam cargos de gestão (coordenadoras, diretoras, entre outros), que, pela natureza do cargo, demanda o trabalho gerencial.

Para que este debate fique mais claro, retomemos o contexto da pandemia. Um paciente com covid-19 precisa de muitos procedimentos assistenciais executados pela enfermeira ou pela técnica em enfermagem: punção, administração de medicação, aspiração (compartilhado com a fisioterapia), mudança de decúbito, entre muitos outros. Mas, para que o procedimento ocorra, alguém precisa prever e prover o material necessário, distribuir o trabalho entre as técnicas de enfermagem e supervisioná-lo e articular junto à (ao) médica(o), fisioterapeuta e demais membros da equipe, que cuidados o paciente terá. E quem realiza toda esta parte gerencial é a enfermeira.

Em um estudo sobre processo de trabalho em saúde, é apontado que a enfermeira realiza, na maioria das vezes, o trabalho de articuladora da equipe de saúde e de coordenadora da equipe de enfermagem. $1,2 \mathrm{E}$, de fato, podemos notar que em um serviço de saúde qualquer, não à toa, quase todas/os trabalhadoras/es, em algum momento, necessitam de informações que são dadas pela enfermeira, seja sobre a existência de um material ou a evolução de um paciente.

Com isto, nota-se que a enfermeira, além do trabalho assistencial, executa um trabalho que podemos dizer que é semelhante ao de um gerente intermediário: providencia insumos, organiza processos de trabalho, faz as articulações para que a assistência seja prestada.

* Vou me referir sempre no feminino, dado que são as mulheres a maior força de trabalho desta profissão. 
Ora, em um serviço como o hospital, cheio de complexidades e de trabalhos distintos, é necessário que alguém "amarre" os nós para que o objetivo final seja alcançado: a realização da assistência ou a satisfação da necessidade do paciente. E o sistema, tanto econômico quanto o de modelo assistencial, encontrou na enfermeira essa trabalhadora.

Durante a pandemia, essa trabalhadora de processo de trabalho dual torna-se fundamental, mas não pelo reconhecimento do trabalho em si, mas porque, no contexto da precarização do trabalho e da necessidade de mais e mais enfermeiras para a realização do trabalho assistencial-gerencial, o preço (salário) dessa força de trabalho tem sido cada vez mais baixo.

São diversas as causas dos baixos salários, mas aqui chamo atenção de uma: as enfermeiras aceitam, por motivos diversos, um salário que sequer paga a parte assistencial do seu trabalho, quiçá a gerencial. Corrobora para isto uma ideologia existente na profissão de que a "enfermeira tem que estar na beira do leito" e que a parte gerencial do seu trabalho "a afasta do paciente". Como essa ideologia casa bem com o que os patrões querem pagar! E assim conseguem uma trabalhadora que executa uma função dual pelo preço da metade de uma!

Outro aspecto a ser levado em consideração na pandemia é que, pela natureza dual, a enfermeira trabaIha antes, durante e depois da sua jornada de trabaIho. Isto porque, muitas vezes, acaba levando para casa aquilo que não consegue dar conta durante o expediente: prepara capacitações, faz as escalas de trabalho, relatórios, dentre outros. Assim, o que temos é a intensificação do trabalho, que já era comum em período pré-pandêmico e que se acentuam agora na pandemia.

Destacaria algumas lições para nosso processo de trabalho que podemos tirar deste período de crise sanitária: 1. É preciso que reconheçamos o nosso processo de trabalho e a sua potencialidade. A enfermeira é a única trabalhadora que assiste-gerencial; 2. É preciso organização política para fazer barrar a precarização do trabalho. A melhoria de salários, jornadas e condição de trabalho não virá por decreto se não tiver mobilização da categoria; 3. É preciso que as enfermeiras reconheçam e se orgulhem do que fazem. O trabalho da enfermeira é socialmente demandado, o que significa que a sociedade precisa deste; 4. As enfermeiras precisam encontrar estratégias para dar visibilidade ao seu processo de trabalho. A crise sanitária pode ser esta oportunidade, caso as enfermeiras ajam coletivamente por meio de suas entidades representativas: sindicato e associação.

E como quinta e última lição que aponto, resgato um trecho de um artigo: "A partir dessa inserção marcada pela experiência, novos saberes se desenvolveram e se desenvolvem continuamente, assegurando à profissão uma contribuição no campo cognitivo. Seja no terreno hospitalar, seja nas frentes da saúde pública, a Enfermagem tem ocupado, nos programas de gestão e coordenação, um espaço de debates e de auto-organização que resulta do domínio de saberes e práticas".

A pandemia pode servir também para que enfermeiras produzam conhecimento, consolidem o seu espaço de atuação e implementem novas práticas em benefício daqueles que são o objeto de nosso trabalho gerencial - técnicas de enfermagem e demais trabaIhadoras/es da saúde - e assistencial - os pacientes.

\section{Referências}

1. Mendes-Gonçalves RB. Práticas de saúde: processos de trabalho e necessidade. In: Mendes-Gonçalves RB. Saúde, Sociedade e História [Internet]. São Paulo: Hucitec; Porto Alegre: Rede Unida; 2017. Disponível em: http://historico.redeunida.org. br/editora/biblioteca-digital/colecao-classicos-da-saude-coletiva/ SaudeSociedadeeHistoria.pdf

\section{Paim JS. Da teoria do processo de trabalho em saúde aos modelos de atenção. In: Mendes-Gonçalves RB. Saúde, Sociedade e História [Internet]. São Paulo: Hucitec; Porto Alegre: Rede Unida; 2017. Disponível em: http://historico.redeunida.org.br/ editora/biblioteca-digital/colecao-classicos-da-saude-coletiva/ SaudeSociedadeeHistoria.pdf}

3. Santos LAC, Faria L. As ocupações supostamente subalternas: o exemplo da enfermagem brasileira. Saude soc. 2008;17(2):35-44. http://dx.doi.org/10.1590/S0104-12902008000200005 